\author{
Karolina Stefaniak \\ Warszawa
}

\title{
KOMPETENCJA MEDIALNA TŁUMACZA
}

Zarys treści: W oparciu o rozróżnienie między kompetencją tłumaczeniową a kompetencjami tłumacza, artykuł wprowadza pojęcie kompetencji medialnej, jako umiejętności krytycznego i kreatywnego korzystania z mediów elektronicznych w pracy tłumacza. Konieczność rozwijania tej kompetencji wynika ze zmieniających się warunków pracy i stale rozszerzającego się zakresu obowiązków tłumacza, a potraktowanie jej jako jednej z kompetencji tłumacza pozwala zachować ostrość pojęcia kompetencji tłumaczeniowej i uwzględnić wypływ nowoczesnej technologii na proces tłumaczenia.

Yompetencja medialna, a także jej związki z kompetencją językową są już Mprzedmiotem zainteresowania pedagogiki i dydaktyki (np. Schell i in. 1999). Termin ten nie jest natomiast rozpowszechniony w translatoryce, chociaż zjawiska, które obejmuje, zostały już częściowo opisane. Przez kompetencję medialną rozumie się umiejętność korzystania z mediów, z naciskiem na świadomy, tj. krytyczny i kreatywny, aspekt ich wykorzystania. Celem artykułu jest omówienie i wyjaśnienie specyfiki kompetencji medialnej tłumacza, czyli wykorzystania mediów (zwłaszcza elektronicznych) w praktyce tłumaczenia. Przed przystąpieniem do dokładniejszego wyjaśnienia tego pojęcia niezbędne jest jednak określenie miejsca kompetencji medialnej w ramach szerszej kompetencji tłumaczeniowej.

Pojęcie kompetencji tłumaczeniowej pojawiło się w latach 70. wraz z wyodrębnieniem się translatoryki jako nauki i od tego czasu jest stale definiowane i redefiniowane. Badacze zazwyczaj są zgodni, że kompetencja tłumaczeniowa nie jest prostą sumą kompetencji językowej w języku źródłowym i docelowym. Jak pisze W. Koller: 
Übersetzungskompetenz als die Fähigkeit, zu einem AS-Text einen bestimmten Forderungen, sog. Äquivalenzforderungen, entsprechenden ZSText herzustellen, ist qualitativ etwas anderes als die Beherrschung der betreffenden Sprachen, die reine Sprachkompetenz. [...] Bilingualismus, d.h. die ganz oder annäherungsweise gleiche Beherrschung zweier Sprachen, nicht zugleich bedeuten muss, dass auch Übersetzungskompetenz gegeben ist. Übersetzungskompetenz ist nicht nur mehr Sprachkompetenz in AS und ZS: man denke etwa an die Anforderungen im Bereich der Fachterminologien, der Syntax und Stilistik der Wissenschaftssprachen, der ästhetischen Qualität literarischer Texte. (Koller 1992: 19)

Podobnie uważa F. Grucza (1981, 1985), który wprowadza pojęcie „kompetencji translatorycznej”, określanej jako „swoista kompetencja bilingwalna”. Swoistość tej kompetencji polega na tym, że właściwości translatoryczne tworzą nadbudowę, uwarunkowaną przez sprawności językowe, ale nie wynikającą $\mathrm{z}$ nich automatycznie. Kompetencja tłumaczeniowa to pewna wiedza, umiejętności i zdolności tłumacza, zarówno te nabywane w procesie akwizycji języka (nieświadome), jak i świadomie rozwijane w procesie kształcenia (Best 2002). Jednak poszczególni autorzy w różny sposób i w różnym zakresie przedstawiają składniki tak rozumianej kompetencji tłumaczeniowej. Liczba kompetencji cząstkowych wchodzących w skład kompetencji tłumaczeniowej jest ograniczana bądź zwiększana, jedne umiejętności traktowane są jako podrzędne wobec innych bądź też wszystkie stawia się na równiej pozycji względem siebie, a możliwości kombinacji wydają się nieograniczone. Ch. Nord (1991) wymienia pięć takich kompetencji cząstkowych: transferu (kompetencja tłumaczeniowa w węższym znaczeniu), językowa, kulturowa, rzeczowa i techniczna, które razem tworzą kompetencję tłumaczeniową. Z kolei G. Hansen (1999) stawia kompetencję tłumaczeniową obok kompetencji społecznej, kulturowej i interkulturowej oraz komunikacyjnej. Kompetencja tłumaczeniowa to z jednej strony umiejętność odczytania informacji z tekstu źródłowego i jej oddania w tekście docelowym, zgodnie $\mathrm{z}$ funkcją tekstu docelowego, $\mathrm{z}$ drugiej zaś strony jest to wiedza o teoriach tłumaczenia, metodach i strategiach (np. umiejętność rozwiązywania problemów tłumaczeniowych) oraz sposobach oceny tłumaczeń. Kompetencja tłumaczeniowa może być więc rozpatrywana jako wiedza i umiejętności niezależne od znajomości poszczególnych języków.

W literaturze najczęściej wymienia się i opisuje następujące kompetencje: językową, rozbijaną na kompetencję języka ojczystego i języka obcego, kulturową i interkulturową, społeczną, komunikacyjną, pragmatyczną, tekstową, specjalistyczną (Snell-Hornby i in. 1999). Wyróżnia się też kompetencję strategiczną, zawodową, psychologiczną, logiczną, encyklopedyczną oraz 
wiele innych cech, które powinien posiadać tłumacz, jak znajomość przedmiotu tłumaczenia, kultura ogólna, zdolności intelektu, zdolność koncentracji, znakomita pamięć, a nawet odporność na zmęczenie, pracowitość czy wreszcie talent i łut szczęścia (Pieńkos 2003). K. Hejwowski (2004a) do elementów kompetencji tłumaczeniowej zalicza przede wszystkim: znajomość języka wyjściowego i docelowego; umiejętność dopasowania do siebie różnych struktur obu języków, znajomość kultury krajów, w których mówi się językiem wyjściowym i docelowym; szeroką wiedzę o świecie, zarówno wiedzę ogólną, jak i specjalistyczną; interpretacyjną i perswazyjną sprawność komunikacyjną; wnikliwość w dążeniu do sensu i niezadowalanie się jedynie płytkim rozumieniem tekstu; znajomość teorii tłumaczenia oraz pewne, raczej trudne do uogólnienia, predyspozycje i cechy charakteru.

Zwiększanie liczby kompetencji niezbędnych tłumaczowi można wyjaśnić $\mathrm{z}$ jednej strony rosnącą interdyscyplinarnością translatoryki i chęcią objęcia jednym pojęciem wszystkich możliwych sytuacji tłumaczeniowych - od tłumaczenia literatury pięknej, przez tłumaczenia przysięgłe, po symultaniczne. $Z$ drugiej strony jest to spowodowane rozwojem technologii i ewolucją zawodu tłumacza. Współczesny tłumacz nie tylko tłumaczy, ale również przeprowadza korektę tekstów przetłumaczonych przez innych tłumaczy, edytuje teksty tłumaczone maszynowo (postedycja), tworzy bazy terminologiczne, pisze abstrakty w języku obcym na podstawie artykułów w języku ojczystym lub odwrotnie - wykonuje zadania związane $\mathrm{z}$ lokalizacją ${ }^{1}$ oraz inne czynności mieszczące się w ramach tzw. language services. Sam tłumacz staje się zaś language service provider - dostawcą usług językowych.

Tak złożone definiowanie kompetencji tłumaczeniowej prowadzi do stopniowego rozmywania tego pojęcia, dlatego też niektórzy autorzy postulują wprowadzenie definicji minimalistycznej, obejmującej tłumaczenie i tylko tłumaczenie. A. Pym $(1991,2003)$ proponuje następującą definicję kompetencji tłumaczeniowej. Ma to być mianowicie:

- umiejętność wygenerowania więcej niż jednego tekstu w języku docelowym na podstawie danego tekstu w języku źródłowym,

- umiejętność wybrania jednego $\mathrm{z}$ wygenerowanych tekstów w języku docelowym oraz

- umiejętność uzasadnienia swojego wyboru.

${ }^{1}$ Lokalizacja to tłumaczenie i adaptacja produktu, takiego jak program komputerowy czy serwis internetowy, do zwyczajów i kultury rynku zagranicznego, biorąc pod uwagę także wymagania formalne i techniczne. Termin „lokalizacja” akcentuje całościowy wymiar dostosowywania produktu do wymagań innych rynków, nie tylko jego aspekt językowy. 
Podejście to A. Pym określa jako minimalistyczne, w przeciwieństwie do szerokiego rozumienia kompetencji tłumaczeniowej, które można by nazwać globalnym. Pewnym sposobem pogodzenia podejścia globalnego i minimalistycznego mogłoby być rozróżnienie między kompetencją tłumaczeniową a kompetencją tłumacza (translation competence vs. translator's competence). W literaturze polskiej oba te terminy używane są wymiennie: w Małej encyklopedii przekładoznawstwa (2000) pod redakcją U. Dąmbskiej-Prokop występuje hasło Kompetencje tłumacza, choć dalej w opisie tego hasła czytamy: „Na kompetencję tłumaczeniową składają się w istocie [...]”. W Tezaurusie terminologii translatorycznej (1998) pod redakcja J. Lukszyna znajduje się hasło Kompetencja tłumacza; jako synonimy tego terminu podano „kompetencja translatorska” i „wiedza tłumacza”. A. Marchwiński (1992) pisze o „właściwościach translatorycznych”, mających stanowić główny przedmiot zainteresowań translatoryki, na które składają się „właściwości pozwalające tłumaczowi przyporządkować treści tekstu wyjściowego tekst docelowy" (Marchwiński 1992: 247) oraz właściwości o charakterze technicznym. B. Kielar $(1986,1988)$ używa terminu „kompetencja translacyjna", pisząc:

Przy określaniu kompetencji translacyjnej na ogół odchodzi się od sformułowań globalnych, które niosą daleko idące uogólnienia i zmierza się raczej do precyzowania wymogów stawianych tłumaczowi działającemu w ramach określonego typu układu translatorycznego, co do którego wiadomo, w jakim kierunku [...] i w jakiej formie [...] odbywa się translacja.

(Kielar 1988: 22)

Przez globalne rozumie więc Kielar podejście określane tu jako minimalistyczne. Rozróżnienie między kompetencją tłumaczeniową a kompetencją tłumacza pozwoliłoby zachować ostrość pojęcia kompetencji tłumaczeniowej, a jednocześnie uwzględnić zmieniające się warunki pracy tłumacza i rodzaje tłumaczenia. Kompetencja tłumaczeniowa (tylko liczba pojedyncza) obejmowałaby zgodnie z programem minimalistycznym wyłącznie umiejętność tłumaczenia (transferu) i byłaby niezależna od konkretnych par językowych i konkretnego układu translatorycznego. Kompetencja tłumacza (możliwa liczba mnoga) obejmowałyby pozostałe kompetencje, umiejętności i cechy tłumacza, rozwijanie i uzupełniane w zależności od sytuacji tłumaczeniowej, par języków i typów tłumaczonych tekstów, tworzyłyby ją konkretne zasady, którymi kieruje się tłumacz w swojej zróżnicowanej działalności, a także właściwości o charakterze warsztatowym. 
Zaproponowane rozróżnienie wymagałoby rozwinięcia i dokładniejszego opisu, nie jest to jednak główny temat niniejszego artykułu, którym jest kompetencja medialna. Wstęp ten był jednak niezbędny, aby móc określić, czym jest kompetencja medialna w stosunku do innych wymienianych $\mathrm{w}$ literaturze kompetencji i umiejętności tłumacza. Przy przyjętym tu minimalistycznym rozumieniu kompetencji tłumaczeniowej i oddzieleniu jej od kompetencji tłumacza kompetencja medialna, jako zależna od sytuacji tłumaczenia i rozwoju techniki, stanowi część kompetencji tłumacza.

Kompetencja medialna obejmuje:

- wiedzę o mediach,

- umiejętność korzystania z mediów,

- krytyczne podejście do mediów,

- kreatywne wykorzystanie ich potencjału (Warkus 2000).

Tak rozumiana kompetencja medialna powinna charakteryzować więc wszystkich członków współczesnego społeczeństwa informacyjnego, nie tylko tłumaczy. Z drugiej strony kompetencja medialna tłumacza wykracza poza kompetencję medialną w ogóle, obejmując pewne specyficzne tylko dla tłumacza umiejętności i wiedzę. W społeczeństwie informacyjnym od każdego oczekuje się np. umiejętności obsługi edytora tekstu czy wyszukiwania informacji w Internecie, podczas gdy znajomości programów tłumaczenia maszynowego, umiejętności korzystania z nich, a także świadomości ich możliwości i ograniczeń można wymagać jedynie od tłumacza²; stanowią one część kompetencji medialnej tłumacza.

Elementom kompetencji medialnej tłumacza poświęcono już wiele uwagi, z jednej strony koncentrując się na mediach pisanych (słowniki, teksty paralelne), $z$ drugiej - na mediach elektronicznych (komputer, Internet). W literaturze spotkać można rozważania na temat zastosowania komputera w tłumaczeniu (Schmitt 1996), skomputeryzowania miejsca pracy tłumacza (Reinke 1996) lub wykorzystania narzędzi ułatwiających tłumaczenie lub

2 Tłumaczenie maszynowe (ang. machine translation) to w szerszym znaczeniu termin obejmujący wszelkie sytuacje tłumaczenia wspomaganego komputerowo. Może to być tłumaczenie wykonywane przez człowieka wspomagane przez komputer (ang. machine assisted human translation, MAHT), np. korzystanie ze słowników elektroniczych czy programów sprawdzania pisowni, tłumaczenie wykonywane głównie przez program komputerowy, ale kontrolowane przez człowieka (ang. human assisted machine translation, HAMT), określane również jako CAT (ang. computerassisted translation), wymagające interwencji tłumacza przed przetwarzaniem tekstu przez komputer, po tym procesie lub $\mathrm{w}$ jego trakcie, albo tłumaczenie $\mathrm{w}$ całości wykonane przez komputer bez ingerencji tłumacza. W węższym znaczeniu tłumaczenie maszynowe obejmuje tylko to ostatnie znaczenie (Hutchins 1986). 
wspomagających pracę tłumacza (Schmitt 1999, Feder 2000). Opisuje się korzystanie ze słowników i tekstów paralelnych (Snell-Hornby 1999, Göpferich 1999), słowników elektronicznych (Neubert 1996), tworzenie i zarządzanie terminologicznymi bazami danych (Schmitz 1994, 1996, Mayer 1990) lokalizację oprogramowania i stron internetowych (Freigang 1996, Gerhardt 1999) oraz wykorzystanie tłumaczenia maszynowego (Haverkort 1991, Bernhard 1994, Reinke 1994, 1997).

Częściowo pojęcie kompetencji medialnej pokrywa się z pojęciem kompetencji technicznej używanym przez $\mathrm{Ch}$. Nord, wydaje się jednak, że to pierwsze jest pełniejsze i lepiej oddaje wiedzę i umiejętności, jakich rzeczywiście oczekuje się od tłumacza. Dotychczasowe podejście do mediów w świetle wcześniej przedstawionej definicji jest albo zbyt szerokie, albo zbyt fragmentaryczne. Po pierwsze stawia na równi wiedzę ogólną o mediach $\mathrm{z}$ wiedzą specyficzną dla tłumacza, np. umiejętność obsługi edytora tekstu i programu typu CAT. Tymczasem umiejętność obsługi komputera czy posługiwania się Internetem są elementami kompetencji medialnej w ogóle i nie wchodzą w skład kompetencji medialnej tłumacza, albo raczej przyjmowane są jako oczywiste, tak jak umiejętność czytania i pisania. Po drugie panuje tendencja do „technicyzacji”, tj. zamiast o kompetencji, rozumianej jako ludzkie umiejętności, zdolności i wiedza, pisze się o „narzędziach”, „programach” czy „systemach". Po trzecie dotychczasowe ujęcia kompetencji medialnej tłumacza są niepełne w tym sensie, iż akcentują jedynie potrzebę posiadania przez tłumacza wiedzy o mediach i kształcenia umiejętności posługiwania się nimi, podczas gdy rzadko zwraca się uwagę na konieczność krytycznego stosunku tłumaczy do wykorzystywanych mediów, a niemal wcale na kreatywność $\mathrm{w}$ wykorzystaniu ich potencjału.

Na kreatywność w tłumaczeniu zwracał uwagę już W. Wills (1988), a obszerną monografię poświęcił temu zagadnieniu P. Kußmaul (2000). Przedstawia on następującą definicję kreatywnego działania:

Eine kreative Leistung entsteht aufgrund einer Problemerkenntnis und stellt etwas Neues dar, das zu einer bestimmten Zeit in einer Kultur von Experten als angemessen akzeptiert wird. (Kußmaul 2000: 20)

Wykorzystanie potencjału mediów w praktyce tłumaczenia będzie więc kreatywne wtedy, kiedy będzie nowatorskie, ale jednocześnie sensowne i przydatne, dopasowane do aktualnego problemu i prowadzące do jego rozwiązania. „Nowatorskie” oznacza takie wykorzystanie mediów, które nie musi być zgodne $\mathrm{z}$ ich pierwotnym lub podstawowym przeznaczeniem. Kreatywność 
rozpoczyna się już w momencie podejmowania decyzji o wykorzystaniu określonych mediów $\mathrm{w}$ określonej sytuacji zgodnie z celem tłumaczenia, ponieważ decyzje takie podejmuje się przy wyborze strategii tłumaczenia, a właśnie na poziomie strategii, a nie techniki, tłumacz może wykazać się kreatywnością (Kußmaul 2000). Kreatywne jest np. wykorzystanie Internetu jako korpusu tekstów, a wyszukiwarki internetowej jako programu konkordancyjnego (Gajek 2002) w poszukiwaniu kontekstów i kolokacji, ale także korpusów stworzonych na potrzeby badań lingwistycznych, takich jak korpus BNC lub PWN. To właśnie kolokacje, czyli typowe połączenia wyrazowe, stanowią dla uczących się języka obcego i tłumaczy największy problem, którego ze względu na swoją ograniczoną objętość nie mogą rozwiązać tradycyjne słowniki.

Internet może być także przydatny w ocenianiu częstości występowania wyrazów i fraz, szukaniu wzorców tekstowych lub tworzeniu korpusów tekstów paralelnych (Eckstein, Sosnowski 2004). D. Siepmann (2004) wskazuje na możliwość wykorzystania korpusów tekstów z Internetu przy szukaniu ekwiwalentów na poziomie leksykalnym, składniowym i tekstowym podczas tłumaczenia na język obcy. Ponieważ jednak manualne wyszukiwanie tekstów, tworzenie korpusów, a później ich przeszukiwanie jest nieefektywne, proponuje wykorzystanie w tym celu komputera. Najpierw należy wyszukać w Internecie strony poświęcone wybranemu tematowi, a po sprawdzeniu, czy tekst na danych stronach został napisany przez rodzimych użytkowników danego języka, zapisać je na twardym dysku. Siepmann radzi zapisać w ten sposób przynajmniej dziesięć stron. Za pomocą dostępnych w Internecie darmowych programów można następnie przekształcić tekst w formacie HTML na format TXT, później przeszukiwać za pomocą programu konkordancyjnego.

$\mathrm{Z}$ drugiej strony do mediów należy mieć także stosunek krytyczny. Współczesny tłumacz zmaga się raczej nie z niedoborem, ale nadmiarem informacji, których wiarygodności nie zawsze może być pewien. W Internecie obok tekstów napisanych przez wiarygodnych autorów, rodzimych użytkowników danego języka, znajdują się też teksty nieznanego pochodzenia, mogące wprowadzać tłumacza w błąd albo same będące tłumaczeniami; nie nadają się więc na źródło ekwiwalentów dla tłumacza. Zdobywające coraz większą popularność pamięci tłumaczeniowe, czyli bazy danych łączące tekst oryginalny i jego tłumaczenie na poziomie zdań, jeżeli nie zawierają tłumaczeń wykonanych przez samego tłumacza, również stanowią niepewne źródło (Siempann 2004, Eckstein, Sosnowski 2004). Wiąże się to zresztą z koniecznością krytycznego stosunku do tłumaczenia maszynowego w ogóle, które może być narzędziem niezwykle przydatnym w pracy tłumacza, ale tylko pod pewnymi warunkami (Stefaniak 2004). O potrzebie ograniczonego zaufania do słow- 
nika dwujęzycznego w procesie tłumaczenia przypomina $\mathrm{z}$ kolei K. Hejwowski (2004b).

Podsumowując, kompetencja medialna jest jedną z kompetencji tłumacza i obejmuje wiedzę, umiejętność korzystania, krytyczne podejście i kreatywne wykorzystanie potencjału mediów w procesie tłumaczenia, przy czym chodzi o te aspekty korzystania z mediów, które są specyficzne dla pracy tłumacza. Kreatywne ich wykorzystanie oznacza zaś działanie nowatorskie, ale jednocześnie akceptowalne i uzasadnione $\mathrm{w}$ danej sytuacji i przy uwzględnieniu celu tłumaczenia. Wprowadzenie pojęcia kompetencji medialnej tłumacza rodzi również pytanie o ewentualne możliwości i metody nauczania tej kompetencji. W tym jednak celu należy najpierw zastanowić się, co powinno być przedmiotem dydaktyki translacyjnej: wyłącznie kompetencja tłumaczeniowa czy może również kompetencja tłumacza, w tym kompetencja medialna. Rozdzielenie tych dwóch pojęć i odpowiedź na powyższe pytanie może więc pomóc $\mathrm{w}$ efektywniejszym kształtowaniu programu zajęć na studiach tłumaczeniowych, uwzględniającego $\mathrm{z}$ jednej strony osiągnięcia translatoryki jako nauki, z drugiej strony wystarczająco elastycznego, aby sprostać rynkowym wymaganiom wobec zawodu tłumacza.

\section{Literatura}

Bernhard, U., 1994, „Maschinelle Übersetzung in der Praxis”, Lebende Sprachen, nr 2, s. 49-52.

Best, J., 2002, „Die Bedeutung der grundsprachlichen Kompetenz in der Übersetzer- und Dolmetscherausbildung", [w:] Übersetzen und Dolmetschen. Eine Orientierungshilfe, Best, J., Kalina, S. (red.), Tübingen, Basel, s. $123-133$.

Dąmbska-Prokop, U. (red.), 2000, Mała encyklopedia przekładoznawstwa, Częstochowa.

Eckstein, M., Sosnowski, R., 2004, Komputer w pracy tłumacza. Praktyczny poradnik, Kraków.

Feder, M., 2000, „Komputerowe narzędzia tłumaczeniowe dla języka polskiego", Lingua Legis, $\mathrm{nr}$ 8, s. 64-71.

Freigang, K.-H., 1996, „Software Lokalisierung. Ein Gegenstand übersetzungswissenschaftlicher Reflexion?", [w:] Übersetzungswissenschaft im Umbruch. Festschrift für Wolfram Wills zum 70. Geburtstag, Lauer, A. i in. (red.), Tübingen, s. 135-146.

Gajek, E., 2002, Komputery w nauczaniu języków obcych, Warszawa. 
Gerhardt, S., 1999, „Software-Lokalisierung”, [w:] Handbuch Translation, Snell-Hornby, M. i in. (red.), Tübingen, s. 213-217.

Göpferich, S., 1999, „Paralleltexte”, [w:] Handbuch Translation, Snell-Hornby, M. i in. (red.), Tübingen, s. 184-186.

Grucza, F., 1981, „Zagadnienia translatoryki”, [w:] Glottodydaktyka a translatoryka, Grucza, F. (red.), Warszawa, s. 9-27.

Grucza, F., 1985, „Lingwistyka, lingwistyka stosowana, glottodydaktyka, translatoryka", [w:] Lingwistyka, glottodydaktyka, translatoryka, Grucza, F. (red.), Warszawa, s. 19-44.

Hansen, G., 1999, „Die Rolle der fremdsprachlichen Kompetenz”, [w:] Handbuch Translation, Snell-Hornby, M. i in. (red.), Tübingen, s. 341-343.

Haverkort, K., 1991, „Was Übersetzer schon immer über maschinelle Übersetzung wissen wollten, sich aber nicht zu fragen trauten", Lebende Sprachen, nr 1, s. 8-12.

Hejwowski, K., 2004a, Kognitywno-komunikacyjna teoria przekładu, Warszawa.

Hejwowski, K., 2004b, „Rola słownika dwujęzycznego w procesie tłumaczenia”, Lingua Legis, nr 14, s. 6-14.

Hutchins, J. W., 1986, Machine translation: past, present, future, Chichester.

Kielar. B. Z., 1986, „O adekwatne ujęcie językowych właściwości tłumacza”, [w:] Problemy translatoryki i dydaktyki translatorycznej, Grucza, F. (red.), Warszawa, s. 29-38.

Kielar, B. Z., 1988, Tłumaczenie i koncepcje translatoryczne, Wrocław.

Koller, W., 1992, Einführung in die Übersetzungswissenschaft, Heidelberg, Wiesbaden.

Kußmaul, P., 2000, Kreatives Übersetzen, Tübingen.

Lukszyn, J. (red.), 1998, Tezaurus terminologii translatorycznej, Warszawa.

Marchwiński, A., 1992, „Kompetencja kulturowa a kompetencja translatorska. Implikacje dydaktyczne", [w:] Jęzk, kultura - kompetencja kulturowa, Grucza, F. (red.), Warszawa, s. 243-255.

Mayer, F., 1990, „Terminologieverwaltungssysteme für Übersetzer”, Lebende Sprachen, nr 3, s. 106-114.

Neubert, A., 1996, „Computers, dictionary makers and translators”, [w:] Übersetzungswissenschaft im Umbruch. Festschrift für Wolfram Wills zum 70. Geburtstag, Lauer, A. i in. (red.), Tübingen, s. 155-168.

Nord, Ch., 1991, Text analysis in translation, Amsterdam-Atlanta.

Pieńkos, J., 2003, Podstawy przekładoznawstwa. Od teorii do praktyki, Kraków.

Pym, A., 1991, „A Definition of Translational Competence, Applied to the Teaching of Translation", [w:] Translation: A Creative Profession: 12th World 
Congress of FIT. Proceedings, Jovanovic, M. (red.), Belgrade, s. 541-546. Pym, A., 2003, „Redefining translation competence in an electronic age. In defence of a minimalist approach", [w:] Meta 48(4), s. 481-497.

Reinke, U., 1994, „Zur Leistungsfähigkeit integrierter Übersetzungssysteme”, Lebende Sprachen, nr 3, s. 97-104.

Reinke, U., 1996, „Der rechnergestützte Übersetzungsarbeitsplatz im Wandel. Von isolierten Einzelsystemen zur integrierten »Translator's Workstation «", [w:] Übersetzungswissenschaft im Umbruch. Festschrift für Wolfram Wills zum 70. Geburtstag, Lauer, A. i in. (red.), Tübingen, s. 169-185.

Reinke, U., 1997, „Integrierte Übersetzungssysteme. Betrachtungen zu Übersetzungsprozess, Übersetzungsproduktivität, Übersetzungsqualität und Arbeitssituation", Lebende Sprachen, nr 3, s. 97-106.

Schell F. i in. (red.), 1999, Medienkompetenz: Grundlagen und pädagogisches Handeln, München.

Schmitt, P. A., 1996, „Computereinsatz in der Translation”, [w:] Übersetzungswissenschaft im Umbruch. Festschrift für Wolfram Wills zum 70. Geburtstag, Lauer, A. i in. (red.), Tübingen, s. 187-196.

Schmitt, P. A., 1999, „Technische Arbeitsmittel”, [w:] Handbuch Translation, Snell-Hornby, M. i in. (red.), Tübingen, s. 186-199.

Schmitz, K.-D., 1994, „Überlegungen zum Einsatz und zur Evaluierung von Terminologieverwaltungssystemen", Lebende Sprachen, nr 4, s. 145-149.

Schmitz, K.-D., 1996, „Verwaltung sprachlicher Einheiten in Terminologieverwaltungssystemen", [w:] Übersetzungswissenschaft im Umbruch. Festschrift für Wolfram Wills zum 70. Geburtstag, Lauer, A. i in. (red.), Tübingen, s. 197-207.

Siepmann, D., 2004, „High-profile translation from the mother tongue into the foreign language: effective translation strategies and implications for translation theory and translator training", Lebende Sprachen, nr 2, s. 56-64.

Snell-Hornby, M. i in. (red.), 1999, Handbuch Translation, Tübingen.

Snell-Hornby, M., 1999, „Wörterbücher”, [w:] Handbuch Translation, SnellHornby, M. i in. (red.), Tübingen, s. 181-184.

Stefaniak, K., 2004, „Języki ogólne, specjalistyczne i kontrolowane a efektywność tłumaczenia maszynowego", Lingua Legis, nr 14, s. 90-96.

Warkus, H., 2000, „Schule und viele Medienformate: Medienkompetenz als Schlüsselqualifikation", [w:] Neue Medien in der Sekundarstufe I und II, Hendricks, W. (red.), Berlin, s. 121-129.

Wills, W., 1988, Kognition und Übersetzen. Zur Theorie und Praxis der menschlichen und maschinellen Übersetzung, Tübingen. 


\section{Media competence of translators}

\section{(summary)}

Based on the distinction between translation competence and translator's competence, the article introduces the concept of media competence of translators, understood as the abilities and skills to use electronic media in the process of translation critically and creatively. The necessity to develop media competence results on the one hand from the evolution of the translator's profession, and on the other hand from the technological development influencing the nature of the translation process. Modern translators do not only translate. They also correct texts translated by others, edit computer-translated texts (post-editing), create and manage terminology databases, write abstracts in one language on the basis of articles written in another one, localize web-pages and so on. Translators become thus language service providers.

This complex situation is reflected in the evolution of the concept of translation competence, which nowadays covers a great many skills and abilities a modern translator has to display, however, it loses at the same time its clarity. A distinction between translation competence and translator's competence enables to maintain this clarity and to address the changing working conditions of translators and different translation situations. Translation competence (only singular) is understood as the ability to generate more than one target text for the source text, select one and justify one's choice. It is independent from the particular language pair and the particular translation situation. Translator's competences (plural) cover all other skills, abilities and qualities of a translator, developed in the course of professional training and used according to the particular situation, language pair and text type. They encompass the principles translators orient to as well as technical skills and abilities.

Media competence is one of the translator's competences and includes the skills and abilities to use electronic media in the process of translation in a creative but also critical way. However, only these aspects of the use of electronic media are concerned that are specific for the translator's profession. The concept of media competence of translators may help structure training courses for future translators more effectively, which exploits the achievements of the translation theory and at the same time is flexible enough to meet the market requirements for the translation profession. 